\section{$\$$ Research Square}

\title{
Analysis and Real-Time Implementation of IoT in Autism
}

\section{Muhammad Javaid Afzal ( $\nabla$ javaidphy@gmail.com )}

Govt. Islamia College Civil Lines Lahore

Muhammad Waseem Ashraf

Government College University, Lahore

\section{Shahzadi Tayyaba}

The University of Lahore, Lahore Pakistan

\section{Farah Javaid}

Govt. APWA College (W) Lahore Pakistan

\section{Research Article}

Keywords: IoT, Smart home, Autism, P2P, Wearable techs, Fuzzy Logic

Posted Date: June 17th, 2021

DOI: https://doi.org/10.21203/rs.3.rs-610012/v1

License: (c) (1) This work is licensed under a Creative Commons Attribution 4.0 International License. Read Full License 


\title{
Analysis and Real-Time Implementation of IoT in Autism
}

Muhammad Javaid Afzal1,*, Muhammad Waseem Ashraf², Shahzadi Tayyaba ${ }^{3}$, Farah Javaid ${ }^{4}$

1 Department of Physics, Govt. Islamia College Civil Lines Lahore, Pakistan; javaidphy@gmail.com

2 Department of Physics (Electronics), G.C. University, Lahore 54000, Pakistan;

muhammad.waseem.ashraf@gmail.com

3 Department of Computer Engineering, The University of Lahore, Lahore 54000,

Shahzadi.Tayyaba@hotmail.com

4 Department of Physics, Govt. APWA College (W) Lahore, Pakistan; farahjavaid71@gmail.com

*Correspondence: javaidphy@gmail.com

\begin{abstract}
:
The present study comprises the importance and use of IoT, smart home, peer-to-peer, and some other different technologies for the betterment of mankind. Artificial intelligence and machine learning are becoming more and more popular in IoT-based smart homes and other techs. The IoT framework has been used to provide a predictable, concrete, and self-paced learning environment and encourages excellent visual information processing. These techs are also useful for special children with autism. They need smart homes, peer-to-peer networking, robot therapy, and wearable techs. In this paper, the authors presented a unique FLC simulation for the behavior of a child with moderate autism. This simulation shows that how IoT, smart home, peer-to-peer technology, ABA therapy, robot therapy, and wearable techs can bring comforts in the life of a child with autism. All of them have long lasted impacts in producing social skills in an ASD person. The 3D graphical figures presented the graphical analysis of a child's social behavior. The simulation presented $50 \%$ betterment change in the social behavior of children and this can be increased up to $87 \%$ by using intensive therapies. It is also verified by Mamdani's method. A real-time implementation of a boy with autism has shown significant improvements in his social skills.
\end{abstract}

Keywords: IoT, Smart home, Autism, P2P, Wearable techs, Fuzzy Logic.

\section{Introduction}

Internet is an innovative invention of previous decades. It is continuously changing into some different types of interconnected software and hardware. It is a kind of interlinked communication either human to human or human to devices. Internet of things is a coordination of electronic systems in which computing devices are interconnected and interrelated. All types of digital and mechanical articles and machines have capabilities to transfer information to interlinked networks. There is no requirement for the interaction of humans in this system [1]. The top eighteen IoT systems with devices are shown below in the following Fig. 1. 


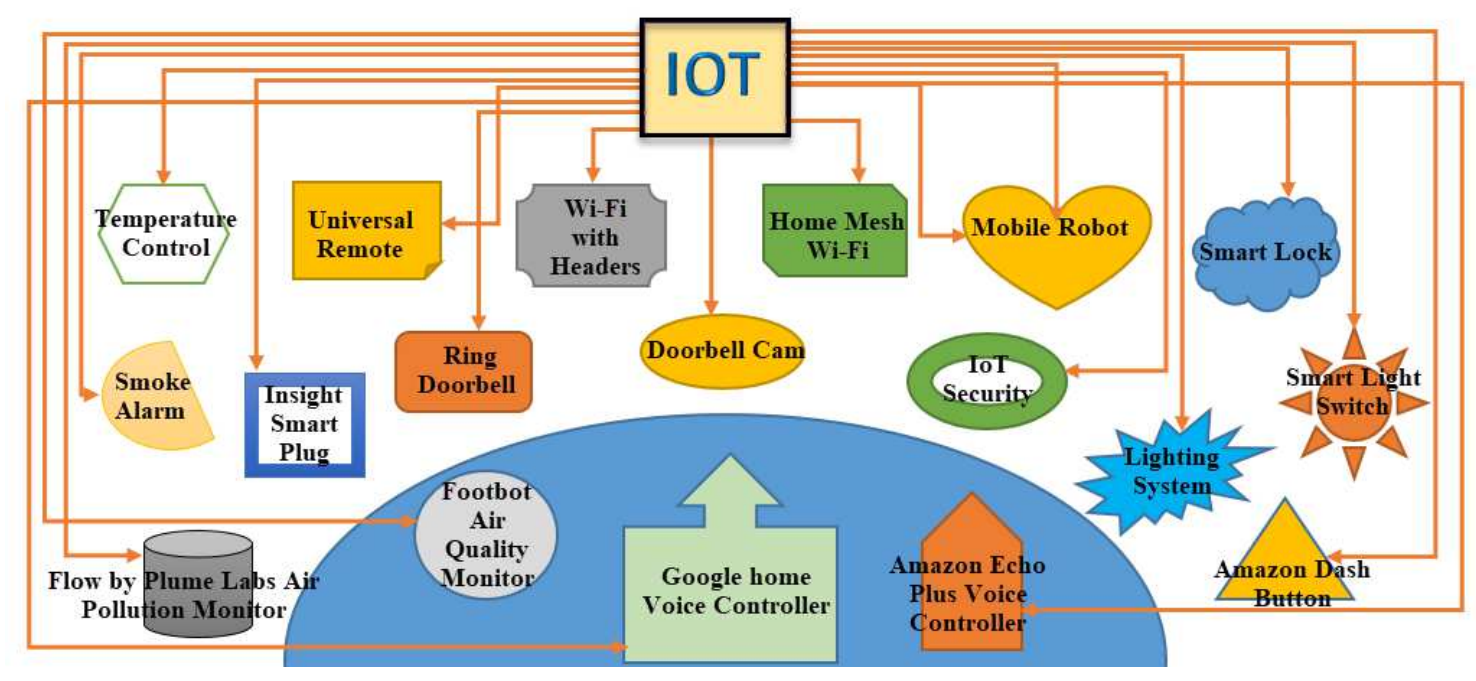

Fig. 1. IOT Systems

Fig. 1. Shows the most important application of IoT is a smart home. It is an internet-connected house in which 24-hour remote monitoring, supervision, and control of all electronic devices have been enabled [2]. It is all about IoT. All home electronic devices can be organized and supervised by using the internet. In recent times, IoT has progressed forward to monitor, control, and supervised every device from fingertip movement and also with voice. This can command a device how to respond and work i.e. when it should turn on and off. Through this way one can set a schedule, set smart TV for videos and music, control smart thermostats control time, money, convenience for benefits, produce alerts and notification on mobile whenever some unexpected event occurs [3]. It is a tension-free system in which one can get rid of failure of electricity, burning fire, and water leakage. These can be the major alerts. It is the new group of smartphones and artificial intelligence. This technology can use Wi-Fi signals to increase its capacity. Through this technology, every light switch, each security system, electrical and electronic devices can communicate with each other [4]. The system of a smart home generally works by the internetconnected hub and can direct signals to every device for its operation and working. Even these devices can be controlled and supervised from millions of miles away from home with mobile phones and voice commands. In this way, precious time and money can be saved [5]. Bedroom temperature can be monitored from your office then actually you are fantasizing about an IoT-based smart home. It can also provide statistical data of using all devices and their electricity bills for payment. Smart home automation can acquire owner's habits and behaviors to modify all settings. With IoT based smart homes locks and garage doors can be opened and closed on the wish of owners with just simple voice commands from anywhere [6]. Smart cameras, smart motion sensors can also be applied to enhance security. Kitchen appliances, make grocery shopping lists and create recipes for cooking, smart refrigerators, and smart coffee makers, keep track of expiration dates, control of cooking devices, washing machines and dryers, sense of a voltage upsurge, sense of water failures, and turn off the water tap in time and every other work related to a home are the most important works for a smart living. This dream can be fulfilled only with IoT based smart home. Artificial intelligence and machine learning are 
becoming more and more popular in IoT-based smart homes [7].

The proper use of all these IoT-based systems, can make our life easy and help a child with autism. Modern therapies need these systems. These electronic systems are smart systems with internet connections. They are capable of interacting with other devices and humans to exchange information. These systems can use the latest technologies like wireless, bluetooth, NFC, LTE, Zig-Bee, and wireless protocols [8]. IoT is now linked in every therapy and the control system to monitor these kids. Mostly, children with autism have interest and get motivation by IoT devices like computers, tablets, laptops, and wearable devices. With these devices, kids get some social interaction. They can respond, make choices, and communicate with others. They can tell their parents, siblings, and teachers what they want to eat, their desire, feel, need and maybe even think. Embedded devices have got fresh advancements in data collection. They can control a large number of smart devices. These devices allow parents to monitor their kids in autism and also in other areas like home electronics and security systems. As these devices become more common, the need will increase for a home networking strategy that will allow all data, voice, and smart devices to be accessed at any time from anywhere. There are some technical software, frameworks, and systems for help in autism which are discussed below. A smart home has shown below in the following Fig. 2.

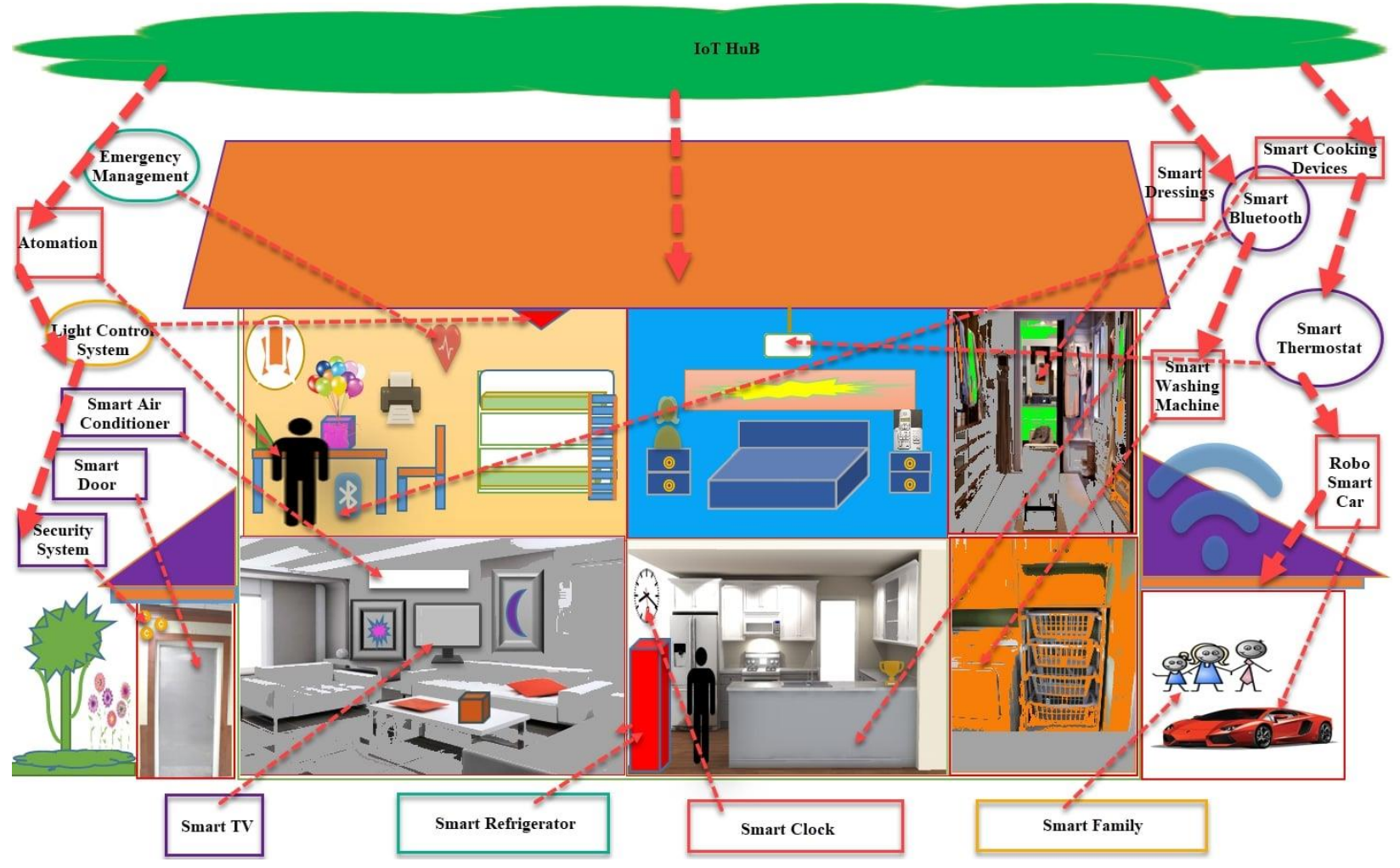

Fig. 2. IOT based Smart Home

Autism is a brain disorder and it shows in spectrum disorder. Kids have these symptoms by birth. These indications present in widespread combinations in the spectrum from mild to severe. Kids having autism have difficulties in communications, interactions, and relations. This 
can compel a child to repeat his or her activities again and again. These children become easily upset when their daily routine changes. They react unusually with strange responses in many conditions [9]. The symptoms of autism can be seen within one year of birth. Babies are not achieving their major milestones after birth like babbling, major motor skills, behavior, and less smiling. Many others milestones are not achievable by these kids. Babies with ASD may be very sensitive to some feelings like touch, smells, some noises, temperature differences, and also with some colors. These kids may develop usual language and social skills but regressive autism takes their skills away in no time. In many cases, they have not developed their languages [10]. They are not just tuned into active kids with cognitive abilities. It does not mean that these kids don't have any abilities. They have abilities, all we have to demonstrate and unleash their abilities out of them and improve their capabilities. Parents believe that childhood vaccines are the reason for developing autism and otherwise. There are many theories of "causation of autism" that exist but no medically proven theory exists [11]. The possible causes of autism are genetics, vaccines, abnormal neural development, mercury preservatives, environment, bad parenting, and traumatic experiences in kids. The use of cellphones, twoway radios, portable telephones, and wireless devices near newborn babies can be the cause of autism. It means electromagnetic radiation can have roots in producing autism [12, 13]. Brain autopsy has shown deficits in numerous portions of the brain. These can be shown in the following Fig. 3.

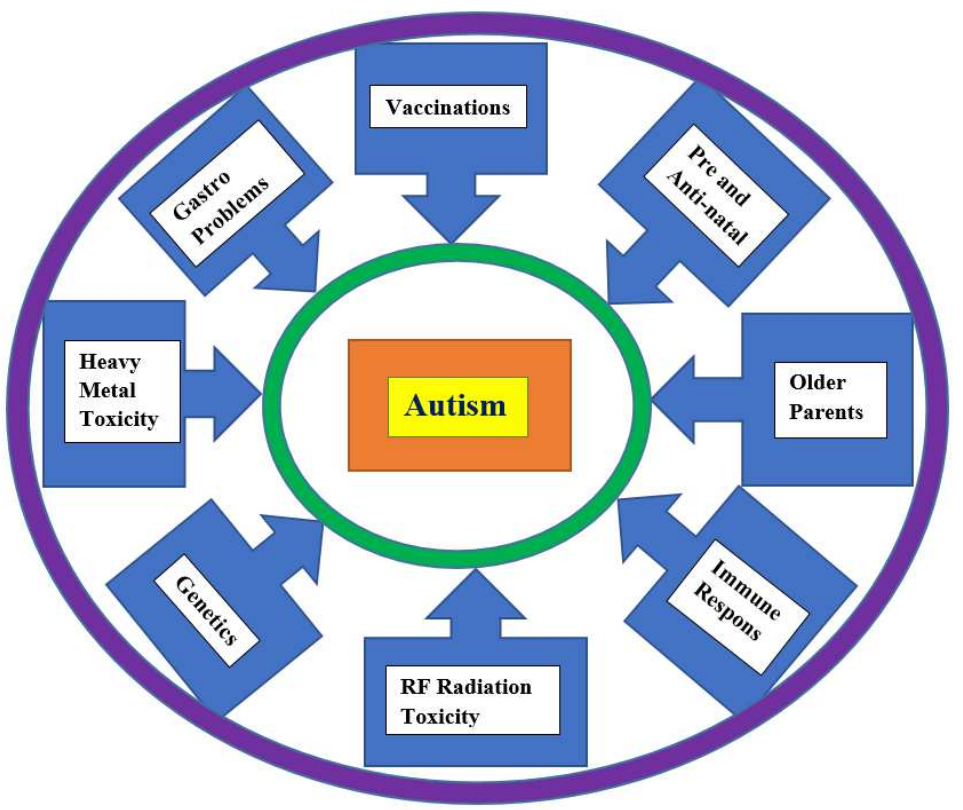

Fig.3. Possible Causes of Autism

Research has not shown any scientific confirmation which supports any type of linkage between vaccinations and autism [14]. Therefore, parents should take care of childhood vaccines as in other normal kids to avoid any other dangerous illness. Researchers indicated that genetic factors can be the cause and they predominated. Autism is complex, and it is difficult to say which genes are the actual causes [15]. There are some cases in which autism is linked with factors that can cause birth defects [16]. There is no cure for autism but some hope is here for these kids. The continual of different types of therapies, pharma, and IoT systems can 
help these kids for an independent, dynamic, and prosperous life [17]. Here in this research, IoT systems for the treatment and better use in therapies are focused.

\section{Peer-to-peer (P2P) computing or networking}

A framework P2P communication amongst kids their parents and therapists is very effective nowadays in autism [18]. It is an architecture of distribution of applications in which that all works and tasks are distributed amongst all peers. In this framework, every peer has an equivalent advantage and can participate in all applications equally. This complete system is said to form a peer-to-peer network of nodes. This framework has been used to provide a predictable, concrete, and self-paced learning environment and encourages excellent visual information processing [19]. It can analyze the behavior of kids with autism. It can store all the data and then therapists can use them for the betterment of the child. This can be shown in the following Fig. 4.

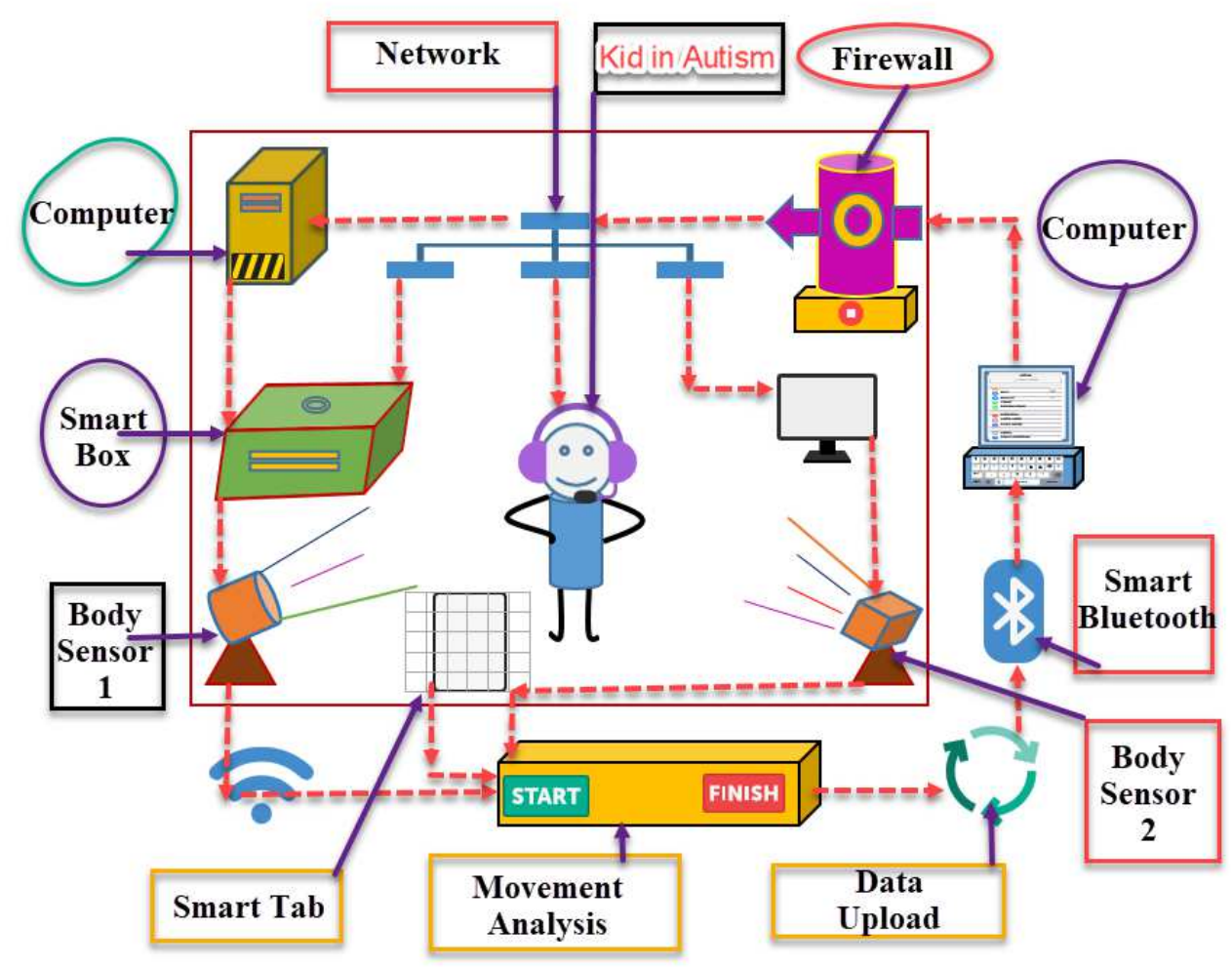

Fig.4. Peer to Peer Framework

There are always challenges for kids with autism. Autism is a source of unease, nervousness, and anxiety for kids and as well as for parents. This technology helps these kids to understand friendship, to understand scripts, characters, images, and visuals, to present realworld rehearsal and practice, to build comforts and interests of these kids, and to think long-term achievements successfully. A newer system for supporting ASD children based on IoT and P2P technology has been introduced. This system uses the JXTA-Overlay platform and Smart Box device to monitor the children and create P2P communication between children, caregivers, and therapists [20]. This system has been Implemented on medical support system using P2P and IoT technologies [21]. IoT systems can provide a programmed monitoring frameworks 
by using sensors and IoT devices, for children with autism. These systems keep track of all data gathered by sensor readings. The data has been obtained from the brain signals of ASD kids. The analysis is performed based on collected data and a report is generated for the therapists. IoT-based health monitoring systems for ASD patients have been worked efficiently [22]. This health monitoring system can be applied as a real-time observation for vital health parameters of ASD children. AutiTRACK is one of the IoT-based monitoring frameworks for ASD children [23].

\section{Applied Behavior Analysis (ABA)}

It is a scientific and systematic methodology to understand the behavior of children with autism. ABA necessitates the implementation of well-known and recognized learning principles, behavior stratagems with environmental adaptations for the improvement of the present behaviors and to teach new future behaviors. This tool was designed for a complete team to help kids with autism. Numerous members of the ABA team must be involved to make this methodology perfect for the needs of these children [24]. This therapy helps to improve new skills and abilities, shape and refine previously learned skills, and (3) decrease socially significant problem behaviors. Applied Behavior Analysis (ABA) therapy is an important tool used in autism. It is a type of intensive therapy that focuses on the principles and techniques of learning theory to help and improvement in the social behavior of the child. This therapy helps them in developing new skills, shaping and refining their previously learned skills, and in decreasing their behavior problems socially.

\section{Use of IoT based Robots in Autism}

Robots can be used in autism as a new therapy tool for children. It is one of the most promising areas in which robots have been introduced for ASD children. Robots have proven their importance in engagement and producing new social behaviors in teenagers and children with autism in novel scientific research. The use of robots in robot therapy is called socially assistive robotics (SAR). SAR can develop robots to comfort people with autism through social interactions $[25,26]$.

\section{Wearable IoT based tech help in autism}

To manage anxiety, people with autism need wearable devices. These devices have proved their authenticity in autism, they are game-changers. A pair of the bracelet, watch, google glasses, necklace, shoelaces, reveal and GPS tracking system can confirm the safety of ASD children [27]. ASD children have a natural difficulty in noticing a danger, in understanding someone's expression, and in judging someone's thinking and feelings precisely. An ASD child can be inspired to escape from a situation that can overstimulate him or her by moving to a safe place in their schools and homes on their own. An IoT-based tracking tech can make this possible. Due to this the location of a child can be monitored if they have moved elsewhere. The software of face recognition has been used in these glasses with a front cam. This tech can sense the facial cues of a stranger and interpret them in the right or left corner of these glasses. ASD kids can see happy and sad emotions through these glasses [28-30]. Therefore, they can develop social skills to recognize strangers. Reveal is an advanced wearable tech with a simple bracelet design. It can sense emotional instants and translate them into useful information. It can sense heart rate, sweat levels, body temperature, and other parameters. This data can transmit to further connected smart devices. In this way, parents can observe the stress levels of their children [31-33]. ASD melt-down issues can grow fast without any reason. It is very hard for parents to identify the real reason for meltdowns. These traumatizing meltdowns can be due to their environment, mind, overstimulation, and interactions. Reveal can track the precise times when they felt most stress [34]. In this way, they can reverse-engineer this fact with the help of 
reveal to determine the exact reason for a meltdown and avoiding it in the future.

\section{Fuzzy Logic Parametric Estimation}

Consider a fuzzy logic controller for therapies in moderate autism (FLCAutism). This controller has five inputs with one output. The inputs are smart home, peer to peer ( $\mathrm{P}$ to $\mathrm{P}$ ), $\mathrm{ABA}$ therapy (ABA), robot therapy (RTh), and wearable techs (WTech) with the behavior of the child as an output. Inputs have three membership functions and output has also three membership functions for decision making. Fuzzy Logic technique is a very innovative technique and a lot of researchers have used this tool in IoT and other fields [35-45]. The controller is shown in the following Fig. 5.

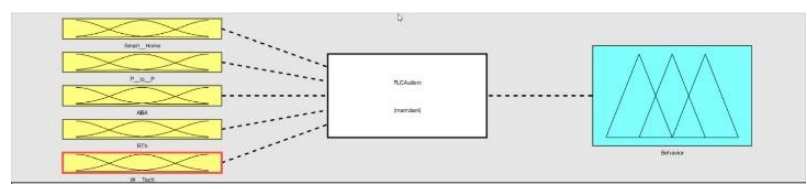

Fig. 5. FLCAutism

The rules for this simulation was set according to the IF and THEN statement. The rule viewer is shown below in Fig. 6.

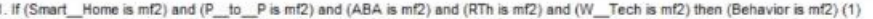

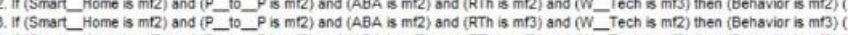

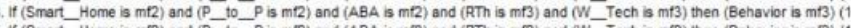
S. (Smar_- Mome is $m(2)$ and (

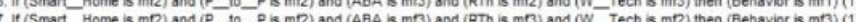

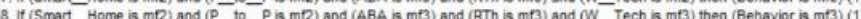

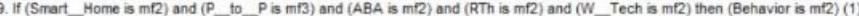

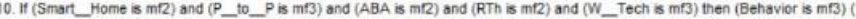

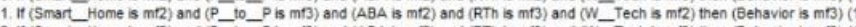

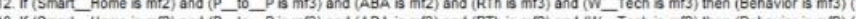

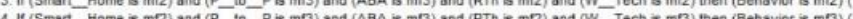

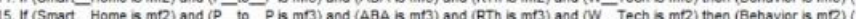

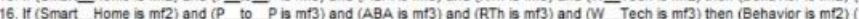

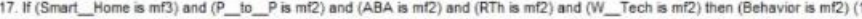
18. If (Smart_Home is $\mathrm{m}(3)$ and (P_ to _ $\mathrm{P}$ is $\mathrm{m} / 2$ ) and (ABA is $\mathrm{m}(2)$ and $(\mathrm{RTh}$ is $\mathrm{m} / 2)$ and (W_ Tech is $\mathrm{m} / 3$ ) then (Behavior is $\mathrm{m}(2)$ (1)

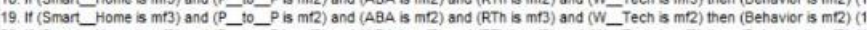

Fig. 6. Rules

The rule viewer Fig. 7. is shown below in which all values are set at $75 \%$. The output is then simulated at $50 \%$. It means every $75 \%$ input value we can get only $50 \%$ output. The value of output can be increased up to $87 \%$ when the values of all inputs must be increased up to $100 \%$.

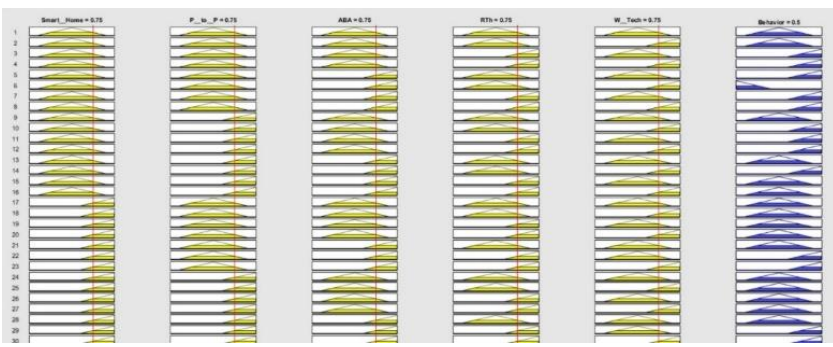

Fig. 7. Rule Viewer

The Fuzzy Logic MATLAB simulated 3D graphs $(a, b, c, d, e, f, g, h, I$, and $j)$ have been shown in the following Fig. 8. 

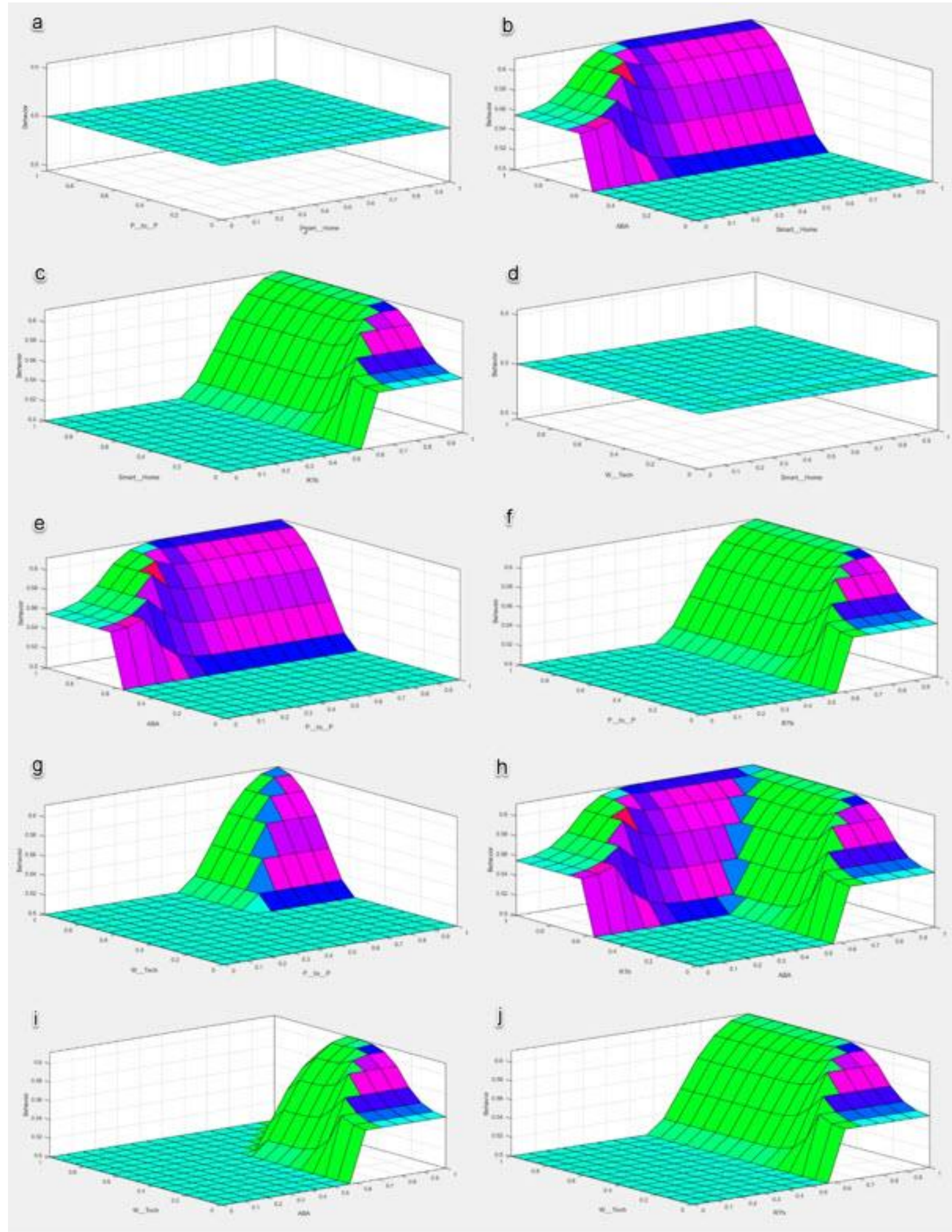

Fig.8. 3D Graphs

The 3D graph "a" has shown only a maximum of $50 \%$ betterment can be achieved in the behavior of a child with moderate autism if only two inputs (P to $\mathrm{P}$ and Smart home) are 
analyzed. This graph shows the even and smooth contributions of these two inputs. It also depends upon the rate of the severity of autism. Here is only moderate autism is considered. In severe autism, it would be very much below $50 \%$. Here, the 3D graph " $b$ " has shown more than $60 \%$ betterment can be achieved in the behavior of a child with moderate autism if only two inputs (ABA and Smart home) are analyzed. This graph shows continuous efforts given to the child with these two inputs. The slope of the graph shows the fast changes in the behavior, once the child is used to it. It also depends upon the rate of the severity of autism. Here is only moderate autism is considered. In severe autism, it would be very much below $50 \%$. Here, the 3D graph " $c$ " has shown more than $60 \%$ betterment can be achieved in the behavior of a child with moderate autism if only two inputs (RTh and Smart home) are analyzed. This graph shows continuous efforts given to the child with these two inputs. The slope of the graph shows the fast changes in the behavior, once the child is used to it. It also depends upon the rate of the severity of autism. Here is only moderate autism is considered. In severe autism, it would be very much below $50 \%$. The 3D " $d$ " graph has shown only a maximum of $50 \%$ betterment can be achieved in the behavior of a child with moderate autism if only two inputs (WTech and Smart home) are analyzed. This graph shows the even and smooth contributions of these two inputs. It also depends upon the rate of the severity of autism. Here is only moderate autism is considered. In severe autism, it would be very much below $50 \%$. Here, the 3D graph " $\mathrm{e}$ " has shown more than $60 \%$ betterment can be achieved in the behavior of a child with moderate autism if only two inputs (ABA and $\mathrm{P}$ to $\mathrm{P}$ ) are analyzed. This graph shows continuous efforts given to the child with these two inputs. The slope of the graph shows the fast changes in the behavior, once the child is used to it. It also depends upon the rate of the severity of autism. Here is only moderate autism is considered. In severe autism, it would be very much below $50 \%$. Here, the 3D graph " $\mathrm{f}$ " has shown more than $60 \%$ betterment can be achieved in the behavior of a child with moderate autism if only two inputs ( $\mathrm{P}$ to $\mathrm{P}$ and $\mathrm{RTh}$ ) are analyzed. This graph shows continuous efforts given to the child with these two inputs. The slope of the graph shows the fast changes in the behavior, once the child is used to it. It also depends upon the rate of the severity of autism. Here is only moderate autism is considered. In severe autism, it would be very much below $50 \%$. Here, the 3D graph " $\mathrm{g}$ " has shown more than $60 \%$ betterment can be achieved in the behavior of a child with moderate autism if only two inputs (WTech and P to P) are analyzed. This graph shows continuous efforts given to the child with these two inputs. The slope of the graph shows the fast changes in the behavior, once the child is used to it. It also depends upon the rate of the severity of autism. Here is only moderate autism is considered. In severe autism, it would be very much below $50 \%$. Here, the 3D graph " $h$ " has shown more than $60 \%$ betterment can be achieved in the behavior of a child in moderate autism if only two inputs (ABA and RTh) are analyzed. This graph shows continuous efforts given to the child with these two inputs. The slope of the graph shows the fast changes in the behavior, once the child is used to it. It also depends upon the rate of the severity of autism. Here is only moderate autism is considered. In severe autism, it would be very much below $50 \%$. Here, the 3D graph " $i$ " has shown more than $60 \%$ betterment can be achieved in the behavior of a child with moderate autism if only two inputs (ABA and WTech) are analyzed. This graph shows continuous efforts given to the child with these two inputs. The slope of the graph shows the fast changes in the behavior, once the child is used to it. It also depends upon the rate of the severity of autism. Here is only moderate autism is considered. In severe autism, it would be very much below $50 \%$. Here, the 3D graph " $\mathrm{j}$ " has shown more than $60 \%$ betterment can be achieved in the behavior of a child in moderate autism if only two inputs (WTech and RTh) are analyzed. This graph shows continuous efforts given to the child with these two inputs. The slope of the graph shows the fast changes in the behavior, once the child is used to it. It also depends upon the rate of the severity of autism. 
Here is only moderate autism is considered. In severe autism, it would be very much below $50 \%$.

\section{Verification through Mamdani's Principal}

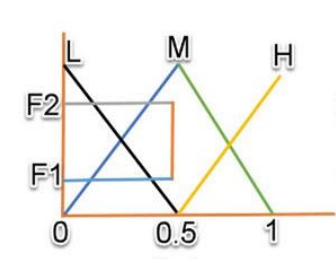

(a)

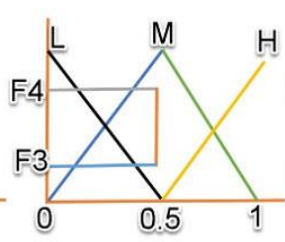

(b)

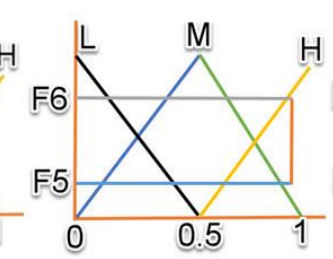

(c)

The simulated value was verified through Mamdani's Principal. Selected inputs and obtained output parametric values are used to design the FLCAutism system. All the regions of the MFs graph are plotted in the following Fig. 9. $(a, b, c, d, e)$.

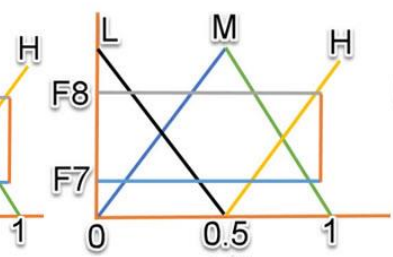

(d)

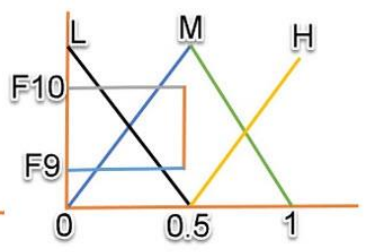

(e)

Fig.9. Regions of MFs graph for inputs

The inputs are smart home, $\mathrm{P}$ to $\mathrm{P}, \mathrm{ABA}$, $\mathrm{RTh}$, and WTech, and their ranges are taken as $(0$, $0.5,1)$. Mf1 is taken as small $(0,0,0.5)$. Mf2 is taken as medium $(0,0.5,1)$. Mf3 is taken as large $(0.5,1,1)$. All values of $F^{\prime}$ s are calculated by Mamdani's method.

$$
\begin{gathered}
F 1=(0.5-0.4) /(1-0.5)=0.2 \\
F 2=1-F 1=0.8 \\
F 3=(1-0.6) /(1-0.5)=0.8 \\
F 4=1-f 3=0.2 \\
F 5=(1-0.8) /(1-0.5)=0.4 \\
F 6=1-f 5=0.6 \\
F 7=(1-0.9) /(1-0.5)=0.2
\end{gathered}
$$

Table.1. all values of F's

\begin{tabular}{|l|l|l|l|l|l|l|l|l|l|}
\hline F1 & F2 & F3 & F4 & F5 & F6 & F7 & F8 & F9 & F10 \\
\hline 0.2 & 0.8 & 0.8 & 0.2 & 0.4 & 0.6 & 0.2 & 0.8 & 0.4 & 0.6 \\
\hline Low & Medium & Low & Medium & Medium & High & Medium & High & Low & Medium \\
\hline
\end{tabular}

Therefore, the singleton values for output behavior are taken as for minimum is 0 , the middle is 0.05 and for high is 0.01 . The values of all $\mathrm{F}^{\prime} \mathrm{s}$ with their levels and all calculations through Mamdani's method are compiled in Tables 1 and 2. 
Table.2. Mamdani's Principal Calculations

\begin{tabular}{|c|c|c|c|c|c|c|c|c|c|}
\hline \multirow{2}{*}{$\begin{array}{l}\text { No. } \\
1 \\
\end{array}$} & \multicolumn{5}{|c|}{ Minimum Membership Function Value } & \multirow{2}{*}{$\begin{array}{c}\text { Behavior } \\
\text { Small }\end{array}$} & \multirow{2}{*}{\begin{tabular}{|c}
$\begin{array}{c}\text { Min value } \\
\mathbf{R i}\end{array}$ \\
0.2 \\
\end{tabular}} & \multirow{2}{*}{$\begin{array}{c}\begin{array}{c}\text { Singleton } \\
\mathbf{S i}\end{array} \\
0 \\
\end{array}$} & \multirow{2}{*}{$\begin{array}{r}\boldsymbol{\Sigma} \mathbf{R i S i} \\
0 \\
\end{array}$} \\
\hline & 0.2 & 0.8 & 0.4 & 0.2 & 0.4 & & & & \\
\hline 2 & 0.2 & 0.2 & 0.6 & 0.8 & 0.6 & Small & 0.2 & 0 & 0 \\
\hline 3 & 0.2 & 0.8 & 0.4 & 0.8 & 0.6 & Medium & 0.2 & 0.005 & 0.01 \\
\hline 4 & 0.2 & 0.8 & 0.6 & 0.2 & 0.4 & Small & 0.2 & 0 & 0 \\
\hline 5 & 0.2 & 0.2 & 0.4 & 0.2 & 0.4 & Small & 0.2 & 0 & 0 \\
\hline 6 & 0.2 & 0.8 & 0.6 & 0.8 & 0.6 & Small & 0.2 & 0 & 0 \\
\hline 7 & 0.2 & 0.2 & 0.4 & 0.8 & 0.6 & Small & 0.2 & 0 & 0 \\
\hline 8 & 0.2 & 0.2 & 0.6 & 0.2 & 0.4 & Small & 0.2 & 0 & 0 \\
\hline 9 & 0.8 & 0.8 & 0.4 & 0.2 & 0.4 & Small & 0.2 & 0 & 0 \\
\hline 10 & 0.8 & 0.2 & 0.6 & 0.8 & 0.6 & Small & 0.2 & 0 & 0 \\
\hline 11 & 0.8 & 0.8 & 0.4 & 0.8 & 0.6 & Small & 0.4 & 0 & 0 \\
\hline 12 & 0.8 & 0.8 & 0.6 & 0.2 & 0.4 & Small & 0.2 & 0 & 0 \\
\hline 13 & 0.8 & 0.2 & 0.4 & 0.2 & 0.4 & Small & 0.2 & 0 & 0 \\
\hline 14 & 0.8 & 0.8 & 0.6 & 0.8 & 0.6 & Small & 0.6 & 0 & 0 \\
\hline 15 & 0.8 & 0.2 & 0.4 & 0.8 & 0.6 & Medium & 0.2 & 0.005 & 0.01 \\
\hline 16 & 0.8 & 0.2 & 0.6 & 0.2 & 0.4 & Small & 0.2 & 0 & 0 \\
\hline & & & Tota & & & & 3.8 & & 0.2 \\
\hline
\end{tabular}

The sum of $\Sigma R i S i$ is 0.02 and $\Sigma R i=3.8$. The value calculated with the help of the equation of Mamdani's Principal is given below.

$$
[\Sigma(\mathrm{Ri} \times \mathrm{Si}) / \Sigma \mathrm{Ri}]{ }^{*} 100=\left(\frac{\Sigma R i S i}{\Sigma R i}\right) X 100=0.52
$$

The results have been evaluated and shown in the table. 3 below. 
Table.3. Result Evaluation

\begin{tabular}{|c|c|}
\hline Category & Behavior \\
\hline Fuzzy Logic value & 0.5 \\
\hline Mamdani's value & 0.52 \\
\hline Difference & 0.02 \\
\hline
\end{tabular}

The above table shows that the simulated value is verified by Mamdani's Principal. This study is limited to just these five inputs and output with only moderate autism. These children with autism also show some type of regression in output. They also can have three levels of autism. These are mild, moderate, and severe autism. In this article, the regression and mild and severe levels of autism have been ignored. The authors will study them in the future.

\section{Real-Time Implementation}

New technologies have been introducing at the beginning of the 21st century to support ASD persons in everyday life and leisure. Children with autism often have problems in communication with their peers, grown-ups, teachers, and parents. In this study, the authors presented an innovative Fuzzy Logic simulation to improve the social skills in children with ASD. These children are observed while playing or using their tablets or laptops while the parents, teachers, and therapists track the child's behavior with IoT, peer-to-peer systems, smart homes, and robot therapies. The real-time implementation of this study on a twelve-year-old boy with autism is shown below. This study is carried over six months period. The improved skills are broken down in the table below.

Table.1. Improved skills with the tool used

\begin{tabular}{|c|l|l|l|c|}
\hline No. & Title & $\begin{array}{l}\text { Remarks } \\
\text { (Before six } \\
\text { months) }\end{array}$ & $\begin{array}{l}\text { Remarks (After six months of } \\
\text { training using IoT devices) }\end{array}$ & Tool used \\
\hline 1. & $\begin{array}{l}\text { Reinforcement } \\
\text { Efficiency }\end{array}$ & Least response & $\begin{array}{l}\text { Responding well to inspiration and } \\
\text { motivation }\end{array}$ & IoT \\
\hline 2. & $\begin{array}{l}\text { Pictorial } \\
\text { Performance }\end{array}$ & $\begin{array}{l}\text { Minimum } \\
\text { response }\end{array}$ & $\begin{array}{l}\text { The capability to understand things } \\
\text { pictorially is much improved. }\end{array}$ & ABA \\
\hline 3. & Language & $\begin{array}{l}\text { Medium } \\
\text { response }\end{array}$ & $\begin{array}{l}\text { The capability to understand verbal } \\
\text { languages is much improved. }\end{array}$ & IoT \\
\hline 4. & $\begin{array}{l}\text { Vocal and Motor } \\
\text { Imitation }\end{array}$ & $\begin{array}{l}\text { Fewer words in } \\
\text { the vocabulary }\end{array}$ & $\begin{array}{l}\text { The capability to imitate the actions } \\
\text { of others and the sounds and words } \\
\text { which others make is much } \\
\text { improved. }\end{array}$ & IoT and ABA \\
\hline 5. & Requirements & Least response & $\begin{array}{l}\text { The capability in demanding things } \\
\text { with the request is much improved. }\end{array}$ & ABA \\
\hline
\end{tabular}




\begin{tabular}{|c|c|c|c|c|}
\hline 6. & Labeling things & $\begin{array}{l}\text { Needs to be } \\
\text { improved }\end{array}$ & $\begin{array}{l}\text { The capability of labeling things, or } \\
\text { their features and purposes is much } \\
\text { improved. }\end{array}$ & $\mathrm{ABA}$ \\
\hline 7. & Verbal behavior & $\begin{array}{l}\text { The intraverbals } \\
\text { of objects are not } \\
\text { present before }\end{array}$ & $\begin{array}{l}\text { The capability of responding to } \\
\text { simple stimulus words is much } \\
\text { improved. }\end{array}$ & IoT \\
\hline 8. & Vocalizations & Less vocalized & $\begin{array}{l}\text { The capability of using language } \\
\text { without being encouraged is much } \\
\text { improved. }\end{array}$ & IoT and $\mathrm{ABA}$ \\
\hline 9. & $\begin{array}{l}\text { Grammar and } \\
\text { Composition }\end{array}$ & $\begin{array}{l}\text { Minimum } \\
\text { speech }\end{array}$ & $\begin{array}{l}\text { The capability of putting words and } \\
\text { sentences together is improved. }\end{array}$ & $\mathrm{ABA}$ \\
\hline 10. & $\begin{array}{l}\text { Playing and } \\
\text { Leisure }\end{array}$ & Self-playing & $\begin{array}{l}\text { The capability of solitary and group } \\
\text { playing skills is improved a bit. }\end{array}$ & $\begin{array}{c}\text { RTh and } \\
\text { Smart home }\end{array}$ \\
\hline 11. & $\begin{array}{l}\text { Social } \\
\text { Communication }\end{array}$ & None & $\begin{array}{l}\text { Capabilities concerning } \\
\text { communication with peers and } \\
\text { grown-ups are improved. }\end{array}$ & ABA \\
\hline 12. & Group Coaching & None & $\begin{array}{l}\text { The capability of learning in groups } \\
\text { is improved. }\end{array}$ & ABA \\
\hline 13. & Classroom Habits & Fewer & $\begin{array}{l}\text { Aptitude in following school rules } \\
\text { and common routines is much } \\
\text { improved. }\end{array}$ & ABA \\
\hline 14. & General Response & None & $\begin{array}{l}\text { The capability to generalize material } \\
\text { learned and use it in real-life or } \\
\text { novel situations is much improved. }\end{array}$ & $\begin{array}{l}\text { ABA and Peer } \\
\text { to Peer with } \\
\text { IoT }\end{array}$ \\
\hline 15. & $\begin{array}{l}\text { Reading } \\
\text { Evaluation }\end{array}$ & $\begin{array}{l}\text { Better in } \\
\text { alphabets }\end{array}$ & $\begin{array}{l}\text { The ability to read sentences are } \\
\text { much improved }\end{array}$ & $\begin{array}{l}\text { Smart Tablet } \\
\text { and ABA }\end{array}$ \\
\hline 16. & Mathematics & Medium level & $\begin{array}{l}\text { The ability to recognize numbers, } \\
\text { their counting, less, greater and } \\
\text { equal, basic types of addition and } \\
\text { subtraction are improved. }\end{array}$ & $\begin{array}{l}\text { IoT, ABA, } \\
\text { Rth, and } \\
\text { Smart } \\
\text { Calculator }\end{array}$ \\
\hline 17. & Writing analysis & Medium level & $\begin{array}{l}\text { The ability of copying, writing on } \\
\text { papers, copies, and on the boards } \\
\text { improved. }\end{array}$ & $\begin{array}{c}\text { IoT, ABA, and } \\
\text { Rth }\end{array}$ \\
\hline 18. & Spelling of words & None & $\begin{array}{l}\text { Spelling learning ability is much } \\
\text { improved. }\end{array}$ & IoT and ABA \\
\hline 19. & Dressing habits & None & $\begin{array}{l}\text { The capability of dressing and } \\
\text { undressing with self-independence } \\
\text { is improved. }\end{array}$ & $\begin{array}{l}\text { Smart tablet } \\
\text { and ABA }\end{array}$ \\
\hline 20. & Eating habits & Messy & $\begin{array}{l}\text { Simple basic self-help abilities } \\
\text { regarding eating and preparing } \\
\text { food are much improved. }\end{array}$ & $\begin{array}{c}\text { IoT, ABA, and } \\
\text { Rth }\end{array}$ \\
\hline 21. & Grooming & Messy & $\begin{array}{l}\text { The ability to control the basic self- } \\
\text { help skills regarding grooming and } \\
\text { hygiene is improved. }\end{array}$ & $\begin{array}{l}\text { Peer-to-Peer, } \\
\text { ABA, and } \\
\text { Smart home } \\
\end{array}$ \\
\hline 22. & Toilet use & Basic & $\begin{array}{l}\text { The capability of self-help skills } \\
\text { regarding toileting is improved. }\end{array}$ & $\begin{array}{l}\text { Smart tablet } \\
\text { and Rth }\end{array}$ \\
\hline
\end{tabular}




\begin{tabular}{|r|l|l|l|c|}
\hline 23. & $\begin{array}{l}\text { Gross Motor } \\
\text { Skills }\end{array}$ & Basic & $\begin{array}{l}\text { Large motor activities such as ball } \\
\text { playing, swaying, swinging, } \\
\text { running, skipping, hopping are } \\
\text { improved. }\end{array}$ & $\begin{array}{c}\text { IoT, ABA, } \\
\text { Rth, and } \\
\text { Smart tools }\end{array}$ \\
\hline 24. & Fine Motor Skills & Basic & $\begin{array}{l}\text { Fine motor activities such as } \\
\text { writing, turn pages of copy or book, } \\
\text { cutting papers, pasting on papers } \\
\text { are much improved. }\end{array}$ & $\begin{array}{c}\text { IoT, ABA, } \\
\text { Rth, and } \\
\text { Smart tools }\end{array}$ \\
\hline 25. & $\begin{array}{l}\text { Facial } \\
\text { recognition }\end{array}$ & Fewer & $\begin{array}{l}\text { The ability to recognize different } \\
\text { faces is improved. }\end{array}$ & $\begin{array}{c}\text { IoT, ABA, and } \\
\text { Smart tools }\end{array}$ \\
\hline 26. & Quran learning & Fewer & $\begin{array}{l}\text { He can recite many Surahs like Ar- } \\
\text { Rehman, Al-Fajar, Wazuha, etc. }\end{array}$ & $\begin{array}{c}\text { IoT, ABA, } \\
\text { and Smart Tv }\end{array}$ \\
\hline
\end{tabular}

Fuzzy and real-time analysis of ASD children has significant importance in fields like motor skills, learning, dressing, verbal, non-verbal expression, human-computer interaction, and other interactions. In this study, the authors presented an assistive system designed for ASD children for improving their social skills and behavior. The system is built up of IoT devices and different new technologies and therapies. The system requires the active participation of teachers, therapists, and parents. They can select skills to learn with analysis of behavior. The complete process is planned to extend parent's care and to support ASD children. In both real-time and simulated areas, the boy with autism made visible progress in enhancing his social behavior.

\section{Conclusion}

Internet of Things IoT device is a burning topic in the current era. It is understood how these smart devices developed by mankind for mankind are impacting in both positive and negative ways. For the betterment of a child with autism IoT, smart home, peer-to-peer technology, ABA therapy, robot therapy, and wearable techs can bring comfort in the life of an ASD child, teenager, and adult. All of them have long lasted impacts in producing social skills in an ASD person. 3D graphs have shown different percentages of betterment in behavior. Accumulative change in behavior with all these five inputs ( $75 \%$ therapies) is just $50 \%$ which can be increased up to $87 \%$ with $100 \%$ intensive therapies. It is also verified by Mamdani's method. The question is whether every child with autism can bear $100 \%$ intensive therapies or not. Usually, these children can't bear intensive therapies. Therefore, $75 \%$ of therapies are considered in this manuscript. Fuzzy logic can be used for deciding for the betterment of behavior percentage. Fuzzy logic describes membership functions to take the perfect decision. The realtime implementation of a boy with autism has shown significant changes in his social behavior.

Conflict: The authors declare no conflict

\section{References}

[1] I. Lee and K. Lee, "The Internet of Things (IoT): Applications, investments, and challenges for enterprises," Business Horizons, vol. 58, pp. 431-440, 2015.

[2] M. R. Alam, M. B. I. Reaz, and M. A. M. Ali, "A review of smart homes-Past, present, and future," IEEE transactions on systems, man, and cybernetics, part $C$ (applications and reviews), vol. 42, pp. 1190-1203, 2012.

[3] R. Kale, M. Sawanand, and V. Inamdar, "Intelligent Homes: Robotics And Al Revolution In Social Life," Our Heritage, vol. 68, pp. 120-131, 2020.

[4] A. Qashlan, P. Nanda, and X. He, "Automated Ethereum Smart Contract for Block Chain Based Smart Home 
Security," in Smart Systems and IoT: Innovations in Computing, ed: Springer, 2020, pp. 313-326.

[5] G. Singh, A. Swarnkar, N. Gupta, and K. Niazi, "A Review of Scheduling Techniques and Communication Protocols for Smart Homes Capable of Implementing Demand Response," in Intelligent Computing Techniques for Smart Energy Systems, ed: Springer, 2020, pp. 505-513.

[6] G. Kyriakopoulos, S. Ntanos, T. Anagnostopoulos, N. Tsotsolas, I. Salmon, and K. Ntalianis, "Internet of Things (IoT)-Enabled Elderly Fall Verification, Exploiting Temporal Inference Models in Smart Homes," International Journal of Environmental Research and Public Health, vol. 17, p. 408, 2020.

[7] I. Machorro-Cano, G. Alor-Hernández, M. A. Paredes-Valverde, L. RodríguezMazahua, J. L. Sánchez-Cervantes, and J. O. Olmedo-Aguirre, "HEMS-IoT: A Big Data and Machine Learning-Based Smart Home System for Energy Saving," Energies, vol. 13, p. 1097, 2020.

[8] S. Cheruvu, A. Kumar, N. Smith, and D. M. Wheeler, "Connectivity Technologies for IoT," in Demystifying Internet of Things Security, ed: Springer, 2020, pp. 347-411.

[9] A. Speaks, "What is autism," Retrieved on November, vol. 17, p. 2011, 2011.

[10] C. Lord, M. Rutter, and P. C. DiLavore, "Autism Diagnostic Observation Schedule--Generic," Dissertation Abstracts International Section A: Humanities and Social Sciences, 1999.

[11] G. Trottier, L. Srivastava, and C.-D. Walker, "Etiology of infantile autism: a review of recent advances in genetic and neurobiological research," Journal of Psychiatry and Neuroscience, vol. 24, p. 103, 1999.

[12] I. M. Thornton, "Out of time: a possible link between mirror neurons, autism and electromagnetic radiation," Medical hypotheses, vol. 67, pp. 378-382, 2006.

[13] R. C. Kane, "A possible association between fetal/neonatal exposure to radiofrequency electromagnetic radiation and the increased incidence of autism spectrum disorders (ASD)," Medical hypotheses, vol. 62, pp. 195197, 2004.

[14] A. Doja and W. Roberts, "Immunizations and autism: a review of the literature," Canadian Journal of Neurological Sciences, vol. 33, pp. 341-346, 2006.

[15] C. M. Freitag, "The genetics of autistic disorders and its clinical relevance: a review of the literature," Molecular psychiatry, vol. 12, pp. 2-22, 2007.

[16] T. L. Arndt, C. J. Stodgell, and P. M. Rodier, "The teratology of autism," International Journal of Developmental Neuroscience, vol. 23, pp. 189-199, 2005.

[17] M. J. Afzal, S. Tayyaba, M. W. Ashraf, F. Javaid, and V. E. Balas, "A case study: impact of Internet of Things devices and pharma on the improvements of a child in autism," in Emergence of Pharmaceutical Industry Growth with Industrial IoT Approach, ed: Elsevier, 2020, pp. 49-83.

[18] A. Sula, E. Spaho, K. Matsuo, L. Barolli, F. Xhafa, and R. Miho, "An loT-Based framework for supporting children with autism spectrum disorder," in Information Technology Convergence, ed: Springer, 2013, pp. 193-202.

[19] C. A. Tomlinson and S. D. Allan, Leadership for differentiating schools and classrooms: Ascd, 2000.

[20] A. Sula, E. Spaho, K. Matsuo, L. Barolli, F. Xhafa, and R. Miho, "A new system for supporting children with autism spectrum disorder based on IoT and P2P technology," International Journal of Space-Based and Situated Computing, vol. 4, pp. 55-64, 2014.

[21] V. Kolici, E. Spaho, K. Matsuo, S. Caballe, L. Barolli, and F. Xhafa, "Implementation 
of a medical support system considering P2P and IoT technologies," in 2014 Eighth International Conference on Complex, Intelligent and Software Intensive Systems, 2014, pp. 101-106.

[22] K. S. Kumar and K. Bairavi, "IoT based health monitoring system for autistic patients," in Proceedings of the 3rd International Symposium on Big Data and Cloud Computing Challenges (ISBCC-16'), 2016, pp. 371-376.

[23] M. Gawannavar, N. Jeyanthi, and R. Thandeeswaran, "AutiTRACK: monitoring autism patients with loT," International Journal of Telemedicine and Clinical Practices, vol. 1, pp. 314322, 2016.

[24] S. Artoni, M. C. Buzzi, M. Buzzi, C. Fenili, B. Leporini, S. Mencarini, et al., "A portable application for supporting ABA intervention," Journal of Assistive Technologies, vol. 7, pp. 78-92, 2013.

[25] B. Scassellati, H. Admoni, and $M$. Matarić, "Robots for use in autism research," Annual review of biomedical engineering, vol. 14, pp. 275-294, 2012.

[26] A. A. Ramírez-Duque, L. F. Aycardi, A. Villa, M. Munera, T. Bastos, T. Belpaeme, et al., "Collaborative and inclusive process with the autism community: $A$ case study in colombia about social robot design," International Journal of Social Robotics, pp. 1-15, 2020.

[27] J. A. Kientz, G. R. Hayes, T. L. Westeyn, T. Starner, and G. D. Abowd, "Pervasive computing and autism: Assisting caregivers of children with special needs," IEEE Pervasive Computing, vol. 6, pp. 28-35, 2007.

[28] G. Steinman and D. Mankuta, "The role of oligopeptides in preventing autism," Medical Hypotheses, vol. 138, p. 109604, 2020.

[29] C. Templeman, F. J. O. Morales, M. Ciliberto, A. Symes, and D. Roggen, "Lessons from hands-free data entry in flexible cystoscopy with Glass for future smart assistance," in Smart Assisted Living, ed: Springer, 2020, pp. 63-87.

[30] Z. Boraston and S. J. Blakemore, "The application of eye-tracking technology in the study of autism," The Journal of physiology, vol. 581, pp. 893-898, 2007.

[31] G. K. Dalapati, L. H. Wong, and F. E. Osterloh, "Research presented at Symposium $\mathrm{P}$ of the 10 th International Conference of Materials and Advanced Technology (ICMAT 2019)," Journal of Materials Chemistry A, 2020.

[32] L. Steier, "Reveal: Fluorescence Enhanced Theragnosis by Designs for Vision," European Journal of Dentistry, vol. 14, pp. 186-188, 2020.

[33] E. B. Torres, R. Rai, S. Mistry, and B. Gupta, "Hidden Aspects of the Research ADOS Are Bound to Affect Autism Science," Neural Computation, vol. 32, pp. 515-561, 2020.

[34] D. Lipsky, From anxiety to meltdown: How individuals on the autism spectrum deal with anxiety, experience meltdowns, manifest tantrums, and how you can intervene effectively: Jessica Kingsley Publishers, 2011.

[35] M. J. Afzal, F. Javaid, S. Tayyaba, M. W. Ashraf, C. Punyasai, and N. Afzulpurkar, "Study of Charging the Smart Phone by Human Movements by Using MATLAB Fuzzy Technique," in 2018 15th International Conference on Electrical Engineering/Electronics, Computer, Telecommunications and Information Technology (ECTI-CON), 2018, pp. 411414.

[36] M. J. Afzal, F. Javaid, S. Tayyaba, M. W. Ashraf, M. Ashiq, and A. AKHTAR, "Simulation of a Nanoneedle for Drug Delivery by Using MATLAB Fuzzy Logic," Biologia, vol. 64, 2018.

[37] M. J. Afzal, F. Javaid, S. Tayyaba, A. Sabah, and M. W. Ashraf, "Fluidic simulation for blood flow in five curved Spiral Microchannel," Biologia, vol. 65, 2019. 
[38] M. J. Afzal, M. W. Ashraf, S. Tayyaba, M. K. Hossain, and N. Afzulpurkar, "Sinusoidal Microchannel with Descending Curves for Varicose Veins Implantation," Micromachines, vol. 9, p. 59, 2018.

[39] M. J. Afzal, S. Tayyaba, M. W. Ashraf, M. K. Hossain, M. J. Uddin, and N. Afzulpurkar, "Simulation, Fabrication and Analysis of Silver Based Ascending Sinusoidal Microchannel (ASMC) for Implant of Varicose Veins," Micromachines, vol. 8, p. 278, 2017.

[40] M. J. Afzal, S. Tayyaba, M. W. Ashraf, and G. Sarwar, "Simulation of fuzzy based flow controller in ascending sinusoidal microchannels," in Robotics and Artificial Intelligence (ICRAI), 2016 2nd International Conference on, 2016, pp. 141-146.

[41] S. Tayyaba, M. J. Afzal, G. Sarwar, M. W. Ashraf, and N. Afzulpurkar, "Simulation of flow control in straight microchannels using fuzzy logic," in 2016 International Conference on Computing, Electronic and Electrical Engineering (ICE Cube), 2016, pp. 213-216.

[42] M. Collotta and G. Pau, "Bluetooth for Internet of Things: A fuzzy approach to improve power management in smart homes," Computers \& Electrical Engineering, vol. 44, pp. 137-152, 2015.

[43] D. Meana-Llorián, C. G. García, B. C. P. Gbustelo, J. M. C. Lovelle, and N. GarciaFernandez, "IoFClime: The fuzzy logic and the Internet of Things to control indoor temperature regarding the outdoor ambient conditions," Future Generation Computer Systems, vol. 76, pp. 275-284, 2017.

[44] P. N. Mahalle, P. A. Thakre, N. R. Prasad, and R. Prasad, "A fuzzy approach to trust based access control in internet of things," in Wireless VITAE 2013, 2013, pp. 1-5.

[45] J. Kaur and K. Kaur, "A fuzzy approach for an loT-based automated employee performance appraisal," Computers,
Materials and Continua, vol. 53, pp. 2438, 2017. 